\title{
ADAPTED ECMO ENTRY CRITERIA FOR NEWBORNS WITH PERSISTENT PULMONARY HYPERTENSION (PPHN) FOLLOWING TREATMENT WITH INHALED NITRIC OXIDE (INO) AND/OR HIGH-FREQUENCY OSCILLATORY VENTILATION (HFOV)
}

\author{
S. van Berkel ${ }^{1}$, M. Binkhorst ${ }^{2}$, A. van Heijst ${ }^{3}$, D. Liem ${ }^{3}$ \\ ${ }^{I}$ Paediatrics, Canisius Wilhelmina Hospital, Nijmegen, ${ }^{2}$ Paediatrics, Hieronymus Bosch Hospital, 's \\ Hertogenbosch, ${ }^{3}$ Paediatrics, Radboud University Nijmegen Medical Centre, Nijmegen, The Netherlands
}

Background and aim: ECMO entry criteria were developed before introduction of iNO and/or HFOV as conservative treatment in newborns with PPHN. Its use reduces ECMO need in good responders. In partial responders it will prolong the conservative treatment and delay starting of ECMO, which may induce lung damage. The aim of this study is to identify $\mathrm{AaDO}_{2}$ values in early stage which will predict the newborns, who will fail treatment with iNO and/or HFOV and ECMO is ultimately needed.

Methods: In a retrospective study (2002-2007) 134 term newborns with PPHN were included. In 57 partial responders, we determined the differences in the decline of $\mathrm{AaDO}_{2}$ during $72 \mathrm{~h}$ of iNO and/or HFOV treatment and in the value of $\mathrm{AaDO}_{2}$ after these $72 \mathrm{~h}$ between newborns that ultimately did $(n=11)$ and did not $(n=46)$ need ECMO.

Results: After $72 \mathrm{~h}$, partial responders not requiring ECMO showed a more profound $\mathrm{AaDO}_{2}$ decrease compared to those who ultimately needed ECMO (median decline 259 (IQR 145-357) vs. 35 (IQR -15-123) $\mathrm{mmHg} ; p=0.0004$ ). A decline $<123 \mathrm{mmHg}$ in $72 \mathrm{~h}$ predicted ECMO need (sensitivity $82 \%$, specificity $80 \%$ ). At $72 \mathrm{~h}, \mathrm{AaDO}_{2}$ was significantly lower in partial responders without ECMO need (335 (IQR 246-470) vs. 570 (IQR 455-590) $\mathrm{mmHg} ; p=0.0006$ ). $\mathrm{An} \mathrm{AaDO}_{2}>561 \mathrm{mmHg}$ at $72 \mathrm{~h}$ predicted ECMO need (sensitivity $64 \%$, specificity $95 \%$ ).

Conclusions: Term newborns with PPHN showing an $\mathrm{AaDO}_{2}>561 \mathrm{mmHg}$ or a decline in $\mathrm{AaDO}_{2}<123$ $\mathrm{mmHg}(20 \%)$ compared to baseline after $72 \mathrm{~h}$ of iNO and/or HFOV treatment should be considered candidates for ECMO. 